\title{
Cerebrospinal fluid immunoglobulin abnormalities in systemic lupus erythematosus
}

\author{
JAN ERNERUDH, ${ }^{*}$ TOMAS OLSSON,$\dagger$ FOLKE LINDSTRÖM $\ddagger$ AND THOMAS SKOGH§ \\ From the Department of Neurology, University Hospital, Linköping. * Department of Neurology, Karolinska \\ Institute, Huddinge University Hospital, Stockholm. $\dagger$ Department of Internal Medicine, University Hospital, \\ Linköping. $\ddagger$ Department of Microbiology, University Hospital, Linköping, $§$ Sweden.
}

SUMMARY Central nervous system (CNS) involvement is a common and important complication in systemic lupus erythematosus. The mechanisms for CNS involvement are poorly understood and reliable diagnostic procedures are lacking. Pairs of serum and cerebrospinal fluid (CSF) specimens from 17 patients with clinical and serological manifestations of systemic lupus erythematosus were analysed. All 11 patients with definite or suspect clinical CNS disorder revealed some kind of abnormality in the CSF, in contrast to three of seven systemic lupus erythematosus patients without CNS disorder. The most prominent findings in systemic lupus erythematosus patients with CNS disorder were immune aberrations with oligoclonal bands on agarose isoelectric focusing (AIF) and elevation of IgG and IgM index, probably reflecting intrathecal production of $\mathrm{IgG}$ and IgM respectively. Intrathecal production of antiviral antibodies was found in four of 12 patients by AIF followed by immunofixation and subsequent autoradiography. An enzyme-linked immunoabsorbent assay (ELISA) could not detect autoantibodies against structural brain antigens.

Involvement of the central nervous system (CNS) has been reported in $50 \% \%^{1}$ and $70 \%^{2}$ of patients with systemic lupus erythematosus. The mechanisms leading to CNS involvement are, however, poorly understood and reliable laboratory diagnostic procedures are lacking. Thus, humoral immune variables in cerebrospinal fluid (CSF) have hitherto been studied only to a minor extent. This contrasts with diseases such as multiple sclerosis and CNS infections, where CSF immunoglobulin aberration have been extensively investigated. One prominent finding in these disorders is the frequent occurrence of intrathecal synthesis of IgG which is manifested by elevated CSF IgG index ((CSF IgG/serum IgG): (CSF albumin/serum albumin) $)^{3}$ and by oligoclonal bands demonstrable by electrophoresis or isoelectric focusing of CSF. ${ }^{4}$ In multiple sclerosis, the biological significance of these phenomena is not clear, but they are of diagnostic aid. ${ }^{4-7}$ In CNS infections it has

Address for reprint requests: Dr Jan Ernerudh, Department of Neurology, University Hospital, S-581 85 Linköping, Sweden.

Received 27 July 1984 and in revised form 7 January 1985. Accepted 14 January 1985 been shown that some of the intrathecally produced immunoglobulins have specificity against the causative microorganism (see ref 8 for review).

In systemic lupus erythematosus with clinical CNS involvement, it has been shown in one previous study that $42 \%$ of the patients had oligoclonal bands in CSF demonstrable by isoelectric focusing. ${ }^{9}$ Findings in systemic lupus erythematosus patients without CNS involvement were, however, not reported. CSF IgG index was determined in another study and found to be elevated in 10 out of 20 systemic lupus erythematosus patients with CNS involvement, while normal values were found in patients without CNS disease. ${ }^{10}$

The present study was done in order to study more extensively the occurrence of humoral immune aberrations in CSF from systemic lupus erythematosus patients with and without clinical evidence for CNS involvement. We have analysed pairs of CSF and serum from 17 patients with systemic lupus erythematosus, 11 of whom had definite or probable CNS involvement. Isoelectric focusing was performed to demonstrate oligoclonal IgG bands, and the CSF IgG was determined, as were the corresponding indices of IgA and IgM. Furthermore, IgG fractions separated by isoelectric focusing 
Table 1 Survey of clinical and serological data

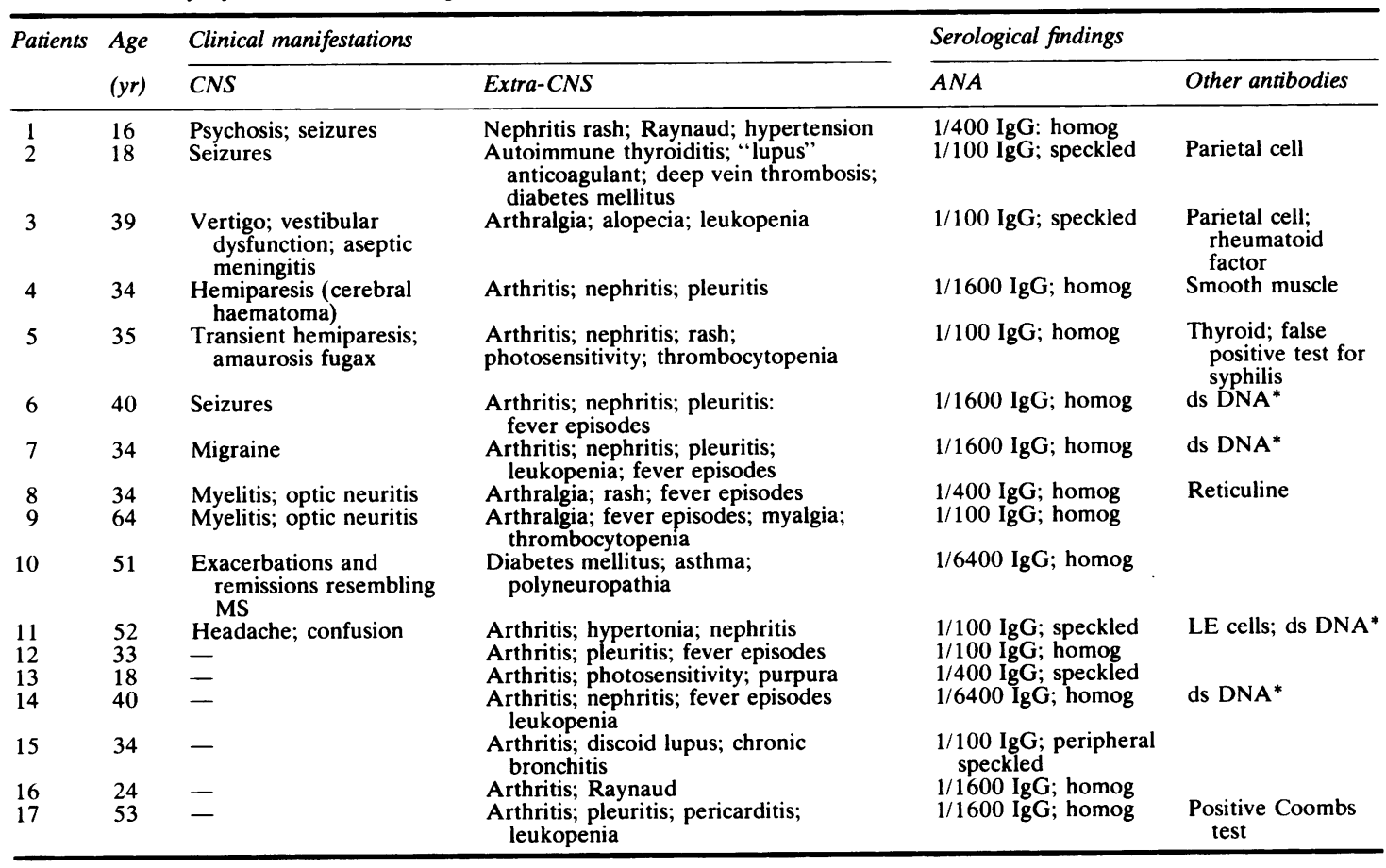

${ }^{*}$ ds DNA $=$ double stranded DNA.

were examined for antiviral and antinuclear antibodies, and an enzyme-linked immunosorbent assay (ELISA) was used to demonstrate any anti-brain IgG antibodies.

\section{Materials and methods}

\section{Patients}

Seventeen patients (14 women) with clinical and serological evidence for systemic lupus erythematosus were included (table 1). Eight of them met the 1982 revised American Rheumatism Association diagnostic criteria," six displayed clinical and serological evidence strongly suggesting systemic lupus erythematosus, two (nos 7,8 ) had signs and symptoms consistent with neuromyelitis optica and had clinical and serological findings suggesting probable systemic lupus erythematosus, and one (no 10) displayed serological findings consistent with systemic lupus erythematosus while the clinical picture was not conclusive for this diagnosis.

Definite systemic lupus erythematosus-related CNS dysfunction was defined as the presence of unequivocal neurological or psychiatric abnormalities not attributable to non-systemic lupus erythematosus causes including corticosteroid therapy. One patient with classical migraine but lacking heredity (No 7) was classified as having probable CNS dysfunction. ${ }^{12}$ CSF and serum used for the present study were always obtained during episodes of neuro- psychiatric symptoms. From one patient (No 6), CSF and serum were obtained during a period when he had no history or signs of CNS dysfunction, and also when he had developed seizures.

Of the 17 patients, 11 (Nos 1-11. table 1) had definite or probable clinical CNS dysfunction (group I), while the remaining six patients (Nos 12-17) as well as patient No 6 examined twice, lacked evidence of CNS involvement (group II).

Control CSF and serum specimens were obtained from four patients who sought advice because of tension headache. The physical and neurological examinations were normal, as were the routine CSF studies.

\section{Routine CSF studies}

$15 \mathrm{ml}$ of CSF was obtained by lumbar puncture, examined for cell numbers by phase contrast microscopy, and centrifuged at $200 \mathrm{~g}$ for $10 \mathrm{~min}$. The erythrocyte count in CSF did not exceed $100 \times 10^{6}$ cells $/ 1$. Determinations of albumin, IgG and IgA were carried out by immunoprecipitation nephelometry on unconcentrated CSF and on serum obtained in parallel. IgM in unconcentrated CSF and in serum was determined by ELISA. ${ }^{13}$ The CSF IgG index was calculated, ${ }^{3}$ as were the corresponding $\operatorname{CSF} \operatorname{IgA}$ and CSF IgM indices. The upper reference limit in our laboratory is 0.7 for the CSF IgG index, 0.6 for the CSF IgA index and 0.06 for the CSF IgM index. As indicator of the blood-brain barrier's status, the CSF albumin/serum albumin ratio was calculated. Age-adjusted upper reference 
values previously described were used. ${ }^{3}$ For demonstration of oligoclonal bands, agarose isoelectric focusing was performed on pairs of CSF and serum. ${ }^{14}$ To confirm the presence of oligoclonal IgG bands, unconcentrated CSF and diluted serum were also examined by agarose isoelectric focusing, followed by transfer to cellulose nitrate membrane, ${ }^{1516}$ and double antibody avidin biotinperoxidase labelling. ${ }^{17}$

\section{Antigen immunofixation and autoradiography for} characterisation of antibody specificity of agarose isoelectric focusing separated $\mathrm{IgG}$

Antigen immunofixation and autoradiography ${ }^{18}{ }^{19}$ was performed to identify antibodies in agarose isoelectric focusing separated CSF and serum IgG against deoxyribonucleic acid (DNA), extractable nuclear antigens (ENA) and various viruses. Briefly, CSF and serum were run by agarose isoelectric focusing and the unstained agarose isoelectric focusing plate was covered with plates containing the antigen dissolved in agarose. Previous experiments using positive and negative serum samples had revealed the following optimal antigen concentrations per ml of agarose; $30 \mu l$ measles (suspension of Lec strain, National Bacteriological Laboratories, SBL, Stockholm, Sweden); $2 \mu$ l herpes simplex virus type 1 (SBL); $10 \mu$ l mumps (Orion, Helsinki, Finland); $10 \mu$ l rubella (Orion); $10 \mu$ l varicella (SBL); $200 \mu$ l DNA (Sigma, St Louis, MO, USA); $200 \mu$ l ENA, a lyophilised phosphate-buffer extract of homogenised calf thymus. ${ }^{20}$ IgG complexed to the antigen was detected by incubation with radiolabelled rabbit anti-human IgG iodinated with 125 I (code IMS 30; the Radiochemical Centre, Amersham, England) using the chloramine-T method,"' and exposed to autoradiography. Patterns on autoradiograms were compared with those on stained agarose isoelectric focusing plates which had been used for immunofixation, and also with agarose isoelectric focusing separated specimens run as reference and stained immediately. Intrathecal antibody production was considered to occur when the most pronounced antibody activity on autoradiography was found in the CSF compared to serum, or when one or more oligoclonal bands on autoradiography were observed in the CSF only, and not in the corresponding serum.

\section{ELISA for identification of IgG antibodies against brain components}

An ELISA previously used in our laboratory to detect autoantibodies in serum and CSF was modified and applied for the detection of any antibodies against the following brain antigens; myelin isolated from CNS of guinea pigs; ${ }^{23}{ }^{24}$ myelin basic protein (MBP) isolated from CNS of human brain from a patient without neurological disease, dying from acute myocardial infarction; water soluble extracts of human grey and white matter, both supernatant and pellet. ${ }^{25}$ The antigens were consistently diluted in $0 \cdot 05 \mathrm{M}$ sodium carbonate buffer $\mathrm{pH} 9 \cdot 6$. Optimal concentrations of CSF and serum, antigens, antisera and incubation times were determined in experiments using positive and negative sera obtained from guinea pigs with chronic relapsing experimental allergic encephalomyelitis ( $r$ EAE). Microtitre plates were coated with $0.1 \mathrm{ml}$ per well of the following antigens; $0.5 \mu \mathrm{g}$ myelin; $0.3 \mu \mathrm{g} \mathrm{MBP}$; $1 \mu \mathrm{g}$ extract of white matter; $1 \mu \mathrm{g}$ extract of grey matter; $1 \mu \mathrm{g}$ pellet of white matter; $1 \mu \mathrm{g}$ pellet of grey matter. CSF containing $0 \cdot 8,4$ and $20 \mathrm{mg} / \mathrm{l}$ of $\mathrm{IgG}$ and serum with $0 \cdot 8,4$, 20,100 and $500 \mathrm{mg} / \mathrm{l}$ of IgG were examined.

Demonstration of autoantibodies against DNA and ENA by indirect immunofuorescence (IF) microscopy

$100 \mu \mathrm{l}$ of serum diluted 1:25 in phosphate buffered saline (PBS, $\mathrm{pH} \mathrm{7.6)}$ and undiluted CSF were allowed to react with $5 \mu \mathrm{m}$ cryostat sections of rat kidney, rat liver and rat stomach for $30 \mathrm{~min}$ at room temperature in a moist chamber. The slides were washed with PBS for $10 \mathrm{~min}$. $100 \mu \mathrm{l}$ fluorescein isothiocyanate-(FITC-) conjugated rabbit anti-human IgG (The Wellcome Foundation Ltd, London, England) was applied to the sections for $30 \mathrm{~min}$. The slides were then washed with PBS, mounted with PBS-buffered glycerine, and examined in a Zeiss Standard microscope equipped with incident halogen lamp illumination and filters for FITC activation/emission. In this way, we looked for antinuclear antibodies (ANA), antimitochondrial antibodies (AMA), anti-smooth muscle antibodies (SMA) and anti-parietal cell antibodies. All ANA-positive sera (1:10) and CSF samples were also tested for presence of antibodies against double-stranded (ds) DNA using the flagellate Crithidia luciliae as source of ds-DNA for indirect immunofluorescence microscopy. Sera giving rise to the speckled type of ANA were analysed for presence of antibodies against ENA, using double immunodiffusion in agarose.

\section{Results}

\section{CSF findings}

All 11 patients belonging to group I with systemic

Table 2 Summary of CSF findings in systemic lupus erythematosus patients with (I) CNS dysfunction (CNS-SLE) and (II) without CNS dysfunction (non CNS-SLE)

\begin{tabular}{|c|c|c|c|c|c|c|c|}
\hline & \multirow[t]{2}{*}{$n$} & \multirow{2}{*}{$\begin{array}{l}\text { Pleocytos }(>5 \\
\text { mononuclear cells } \\
\left.\times 10^{\circ} / \mathrm{l}\right)\end{array}$} & \multirow{2}{*}{$\begin{array}{l}\text { Blood-brain barrier } \\
\text { dysfunction ( } \uparrow C S F / S \\
\text { albumin ratio) }\end{array}$} & \multicolumn{4}{|c|}{ Intrathecal Ig synthesis } \\
\hline & & & & $\begin{array}{l}\lg G \\
\text { index }\end{array}$ & $\begin{array}{l}\lg A \\
\text { index }\end{array}$ & $\begin{array}{l}\lg M \\
\text { index }\end{array}$ & $\begin{array}{l}\text { Oligoclonal IgG } \\
\text { on isoelectric } \\
\text { focusing }\end{array}$ \\
\hline $\begin{array}{l}\text { I CNS-systemic lupus } \\
\text { erythematosus } \\
\text { II non CNS-systemic }\end{array}$ & 11 & 3 & 7 & 6 & 1 & 7 & 9 \\
\hline lupus erythematosus & 7 & 0 & 1 & 0 & 0 & 2 & 0 \\
\hline
\end{tabular}




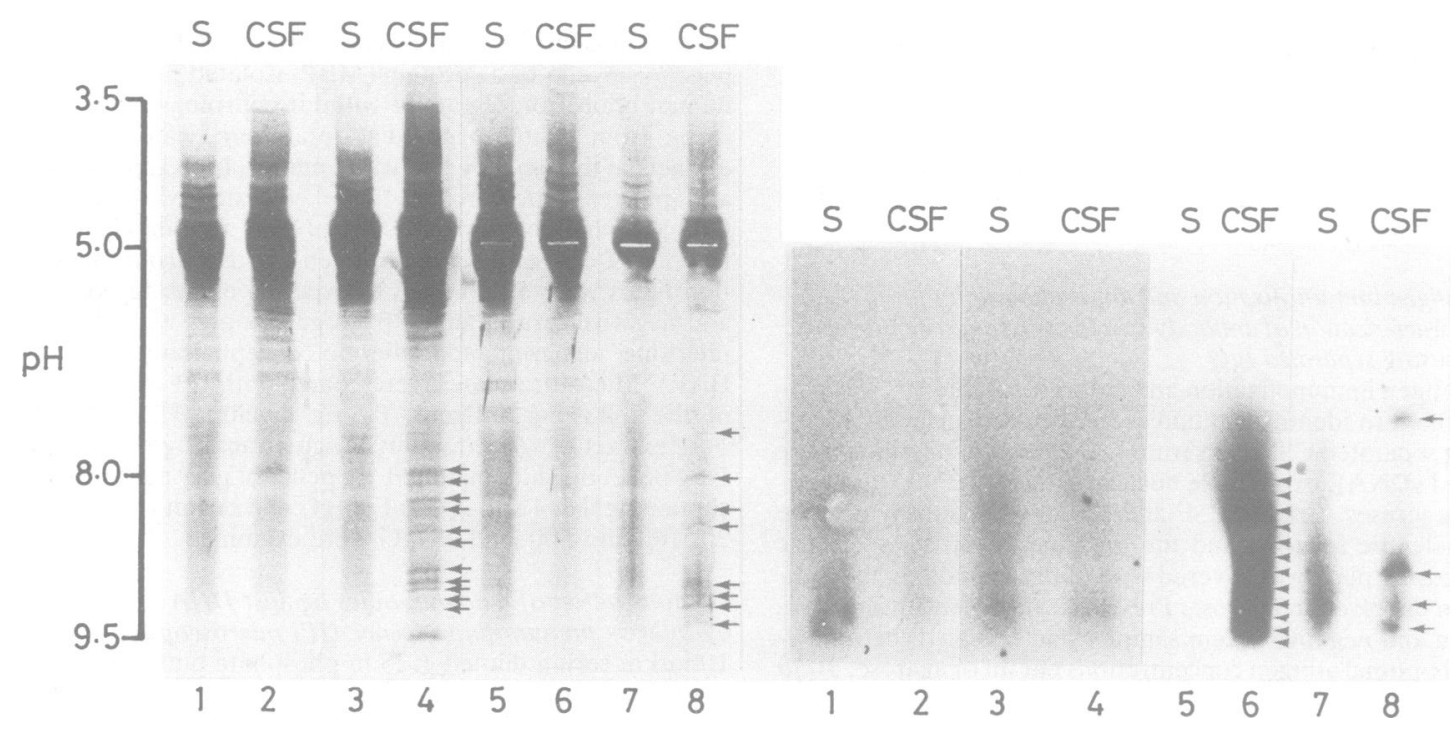

Fig 1 Examples of serum and CSF agarose isoelectric focusing (left 1-8) with corresponding antiviral immunofixation and subsequent autoradiography (right 1-8). 1-2 show normal findings on agarose isoelectric focusing and also on autoradiography, where serum shows some antibody activity, but CSF to a lesser extent. The next patient (sample 3-4) was one with CNS involvement where CSF reveals oligoclonal bands, indicated with arrows. Autoradiography findings are similar to the first patient. Autoradiogram of the next patient (5-6) shows a more pronounced activity (indicated with arrows) in CSF compared to serum. The last patient (7-8) was one with CNS involvement. CSF reveals oligoclonal bands on agarose isoelectric focusing. Arrows on autoradiogram denote zones of pronounced activity compared to serum.

lupus erythematosus and definite or probable CNS dysfunction displayed some abnormality on routine CSF studies, in contrast to three of the seven patients in group II with systemic lupus erythematosus and no CNS dysfunction (table 2). Among the patients of group I, three had mononuclear pleocytosis, seven slight blood-brain barrier damage, nine had oligoclonal bands which were found in CSF only and not in serum by agarose isoelectric focusing (fig 1), and which were proved to consist of $\mathrm{IgG}$ when CSF was re-examined by agarose isoelectric focusing and subsequent double antibody avidin-biotin-peroxidase labelling. Six of the patients of group I had elevated CSF IgG index (fig 2), one of them in the absence of oligoclonal bands, while one had increase of CSF IgA index and seven out of nine examined from group I had elevated CSF IgM index (fig 3). Among the patients of group II, one displayed slight blood-brain barrier damage and two had elevated CSF IgM index. From six of the patients belonging to group $I$, three or more pairs of CSF and serum were obtained during a period of one to five years. The oligoclonal band pattern persisted unchanged in one patient (No 3), showed the appearance of one band and the loss of three other bands in another patient (No 9) and revealed oligoclonal bands only in the first of three consecutive CSF samples in a third patient (No 11). In a fourth patient (No 8) no oligoclonal bands were present in the first CSF sample. Five years later,

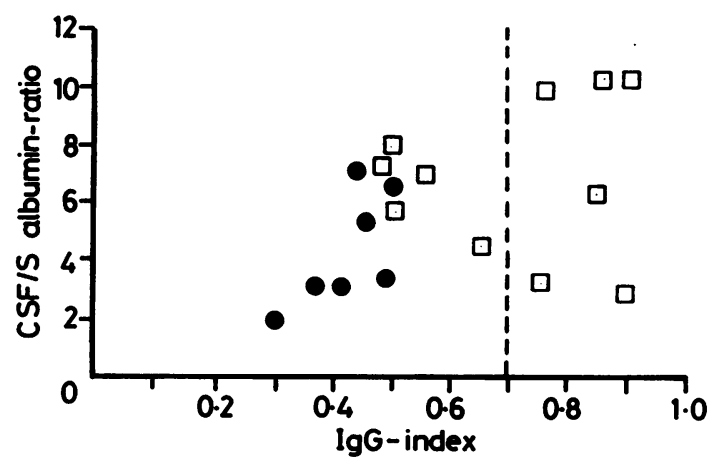

Fig 2 IgG-index versus $C S F / S$ albumin ratio illustrates intrathecal IgG synthesis and blood-brain barrier dysfunction respectively. Open symbols represent systemic lupus erythematosus patients with clinical CNS involvement and closed symbols represent systemic lupus erythematosus patients without clinical CNS involvement. 


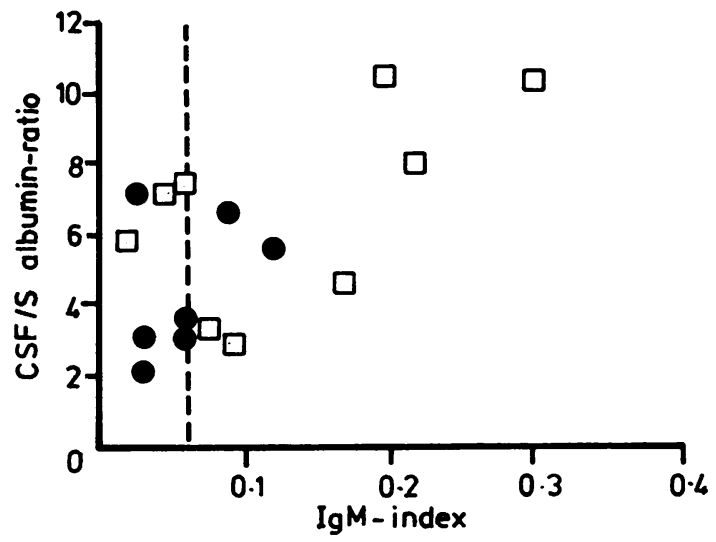

Fig 3 IgM index and CSF/S albumin ratio in systemic lupus erythematosus patients with clinical CNS dysfunction (open symbols) and without clinical CNS involvement (closed symbols).

after additional CNS symptoms (transitory sensory disturbances as in ischaemic attacks), an oligoclonal IgG band pattern was found. The two remaining patients who were followed longitudinally (Nos 1 and 6) did not display oligoclonal bands at any occasion. One of these patients (No 6) was evaluated prior to, during and after occurrence of CNS dysfunction. While having no CNS symptoms, an elevation of the CSF IgM index was the only abnormality. After CNS symptoms had occurred, the CSF IgM index was further raised and CSF IgG index was also elevated. The CSF/serum albumin ratio was also increased, but not high enough to explain the elevated CSF IgM and IgG indices. ${ }^{26}$ After treatment with steroids and plasmapheresis, the CSF IgG index became normal, while the CSF IgM index as well as the CSF/serum albumin ratio remained elevated.

\section{Intrathecal antibody production}

Agarose isoelectric focusing of CSF and serum from 12 of the systemic lupus erythematosus patients and the four control patients, and subsequent immunofixation with viral antigens and autoradiography revealed IgG antibodies against one or more of the viruses tested in most sera. The same antibodies, displaying identical migration properties, were mostly detected in the corresponding CSF, but they appeared less pronounced indicating transudation from serum to CSF. However, in four patients (three with CNS involvement) the CSF revealed stronger bands than in the corresponding serum against herpes simplex virus or varicella, indicating intrathecal antibody synthesis. These viral anti- bodies corresponded to oligoclonal IgG in two of the patients (fig 1).

None of the 14 systemic lupus erythematosus patients examined for intrathecal production of antibodies against DNA or ENA was positive when antigen immunofixation and autoradiography was performed on agarose isoelectric focusing separated CSF and serum, while indirect immunofluorescence revealed DNA-ENA antibodies in CSF in one patient, but at a lower titre than in the corresponding serum.

Using ELISA for identification of IgG antibodies against structural brain components in the form of myelin, myelin basic protein and water soluble extracts of grey and of white matter did not reveal such autoantibodies in CSF or serum from any of the 12 patients examined.

\section{Discussion}

The present study clearly demonstrates aberrations of CSF immunoglobulins in a majority of systemic lupus erythematosus patients with clinical CNS involvement compared to patients without CNS symptoms. The occurrence of these aberrations shows that a thorough examination of CSF including determination of CSF IgG, CSF IgA and CSF IgM indices as well as separation by agarose electrophoresis or preferably agarose isoelectric focusing should be performed in patients with systemic lupus erythematosus who develop clinical evidence of CNS involvement. Cell counting and evaluation of the blood-brain barrier preferably also with determination of the $\mathrm{CSF} / \mathrm{serum}$ albumin $\mathrm{ratio}^{3}$ should be included. Notably, systemic lupus erythematosus patients without clinical CNS involvement lacked CSF IgG abnormalities. On the other hand, systemic lupus erythematosus patients with CNS involvement may lack CSF IgG abnormalities, and normal findings on CSF studies does not exclude CNS involvement in systemic lupus erythematosus.

The immunoglobulin abnormalities observed in systemic lupus erythematosus with CNS involvement are not restricted to IgG but include elevation of the CSF IgM index and occasionally of the CSF $\operatorname{IgA}$ index. It is not clear why two of our patients without clinical CNS involvement also had increased CSF IgM index values. IgM may appear early during immune response and the observed intrathecal IgM synthesis in these patients could indicate early "subclinical" CNS involvement. In fact, one of the systemic lupus erythematosus patients with an elevated CSF IgM index later developed CNS symptoms, and had at that time also an elevated CSF IgG index.

The CSF abnormalities observed in systemic lupus 
erythematosus with CNS involvement, namely mononuclear pleocytosis, slight blood-brain barrier damage and intrathecal IgG and IgM synthesis, are similar to those in multiple sclerosis. ${ }^{4-7131426}$ It remains to be established whether intrathecal IgG and $\operatorname{IgM}$ production in multiple sclerosis has any pathogenetic importance or represents an epiphenomenon. Studies hitherto reported have failed to define antibody specificity of the major portion of intrathecally produced IgG which migrates as oligoclonal bands on electrophoresis or isoelectric focusing. ${ }^{28}$ A minor portion represents a variety of viral antibodies which are most probably synthesised intrathecally, but their relevance to the pathogenesis of multiple sclerosis is unknown. Autoantibodies have not been traced to oligoclonal IgG in multiple sclerosis. ${ }^{28}$

Our results obtained with immunofixation and autoradiography, using viruses as antigens, revealed similarities with the situation in multiple sclerosis. Patients with systemic lupus erythematosus and CNS involvement are thus able to synthesise viral antibodies intrathecally. In the present study none of four normal control patients showed intrathecal antiviral antibody production. In a previous study using the same method, intrathecally produced antiviral antibodies were found in two of 11 control patients, and in 21 of 25 multiple sclerosis patients. ${ }^{29}$

For structural brain antigens, our ELISA technique has successfully demonstrated autoantibodies against various antigens in r-EAE.$^{23}$ It has also been applied to CSF and serum samples from multiple sclerosis patients, where about one third of the patients showed low levels of antibodies against myelin basic protein.

Regarding antiviral antibodies four of 12 patients showed intrathecal production. Judged from previous experiments in multiple sclerosis, these antiviral antibodies account for only a minor proportion of the oligoclonal IgG. ${ }^{1819}$ Present observations of intrathecal antiviral antibody synthesis represent a further similarity with multiple sclerosis where intrathecal synthesis of antibodies against 17 different viruses have been detected. ${ }^{30}$ The deversity of hitherto detected antibody specificities and the large proportion of IgG with unknown antibody specificity (at least, it is not directed against putative autoimmune target antigens) may be interpreted as a random selection of B cells into the CNS compartment during the inflammatory process, and that they for some reason continued to produce IgG (Emerudh, Olsson, unpublished observations).

In conclusion, the present study showed intrathecal synthesis of IgG and IgM in a large proportion of systemic lupus erythematosus patients with CNS involvement, in contrast to patients with- out CNS symptoms. CSF studies with regard to mononuclear pleocytosis, CSF IgG and IgM indices, and oligoclonal IgG bands are therefore useful clinically. The biological and pathogenetic implications of this immune response are unclear.

We thank Professor Hans Link, Department of Neurology, Huddinge University Hospital, Stockholm, for valuable critical review of the manuscript. The excellent technical assistance of Mrs Monica Dufmats, Mrs Ingela Lilja and Mrs Gunnel Rosén is gratefully acknowledged. The work was supported by grants from the Swedish Medical Research Council (project 3381) and Östergötlands Läns Landsting (project 83/28 and 83/26).

\section{References}

' Grigor R, Edmond J, Lewkonia R. Systemic lupus erythematosus. A prospective analysis. Ann Rheum Dis 1978;37:121-8.

${ }^{2}$ Estes D, Christian CL. The natural history of systemic lupus erythematosus by prospective analysis. Medicine 1971;50:85-95.

${ }^{3}$ Tibbling G, Link H, Öhman S. Principles of albumin and IgG analyses in neurological disorders. I. Establishment of reference values. Scand J Clin Lab Invest 1977;37:385-90.

${ }^{4}$ Link H, Müller R. Immunoglobulins in multiple sclerosis and infections of the nervous system. Arch Neurol 1971;25:326-44.

${ }^{5}$ Trotter JL, Brooks BR. Pathophysiology of cerebrospinal fluid immunoglobulins. In: Neurobiology of cerebrospinal fluid; Wood JH, ed. New York: Plenum Press, 1980:465-85.

${ }^{6}$ Link H, Tibbling G. Principles of albumin and IgG analyses in neurological disorders. III. Evaluation of IgG synthesis within the central nervous system in multiple sclerosis. Scand J Clin Lab Invest 1977;37:397-401.

' Thompson EJ, Kaufmann P, Shortman RC, Rudge P, McDonald WI. Oligoclonal immunoglobulins and plasmacells in spinal fluid of patients with multiple sclerosis. $\mathrm{Br}$ Med J 1979; 1: 16-27.

${ }^{8}$ Link H, Kam-Hansen S, Forsberg P, Henriksson A. Humoral and cellular immunity in patients with acute aseptic meningitis. Immunology of nervous system infections. Prog Brain Res 1983;59:29-46.

" Winfield JB, Shaw MBS, Silverman LM, Eisenberg RA, Wilson HA, Koffler D. Intrathecal IgG synthesis and blood-brain barrier impairment in patients with systemic lupus erythematosus and central nervous system dysfunction. Am J Med 1983;74:837-44.

${ }^{10}$ Seibold JR, Buckingham RB, Medsger Jr TA, Kelly RH. Cerebrospinal fluid immune complexes in systemic lupus erythematosus involving the central nervous system. Semin Arthritis Rheum 1982;12:68-76.

"Tan EM, Cohen AS, Fries JF, Alfonse TM, et al. The 1982 revised criteria for the classification of systemic lupus erythematosus. Arthritis Rheum 1982;25: 1271-7. 
${ }^{12}$ Brandt KD, Lessell S. Migrainous phenomena in systemic lupus erythematosus. Arthritis Rheum 1978; 21:7-16.

${ }^{13}$ Forsberg P, Henriksson A, Link H, Öhman S. Reference values for CSF-IgM, CSF-IgM/S-IgM ratio and IgM index, and its application to patients with multiple sclerosis and aseptic meningoencephalitis. Scand $J$ Clin Lab Invest 1984;44:7-12.

${ }^{14}$ Link H, Kostulas V. Utility of isoelectric focusing of cerebrospinal fluid and serum on agarose evaluated for neurological patients. Clin Chem 1983;29:810-5.

is Glynn P, Gilberg H, Newcombe JIA, Cuzner ML. Rapid analysis of immunoglobulin isoelectric focusing patterns with cellulose nitrate sheets and immunoperoxidase staining. J Immunol Methods 1982;51:251-7.

${ }^{16}$ Walker RWH, Keir G, Johnson MH, Thompson EJ. A rapid method for detecting oligoclonal IgG in unconcentrated CSF, by agarose isoelectric focusing, transfer to cellulose nitrate and immunoperoxidase staining. J Neuroimmunol 1983;4:141-8.

${ }^{17}$ Olsson T, Kostulas V, Link H. Detection of oligoclonal IgG in unconcentrated CSF by agarose isoelectric focusing and double antibody avidin-biotinperoxidase labelling. Clin Chem 1984;30:1246-9.

${ }^{18}$ Nordal HJ, Vandvik B, Norrby E. Multiple sclerosis: local synthesis of electrophoretically restricted measles, rubella, mumps and herpes simplex virus antibodies in the central nervous system. Scand $J$ Immunol 1978;7:473-9.

${ }^{19}$ Shorr J, Roström B, Link H. Antibodies to viral and non-viral antigens in subacute sclerosing panencephalitis and multiple sclerosis demonstrated by thin-layer polyacrylamide gel isoelectric focusing, antigen immunofixation and autoradiography. $J$ Neurol Sci 1981;49:99-108.

${ }^{20}$ Sharp GL, Williams SI, Tan EM, Gould RG, Holman HR. Mixed connective tissue disease - an apparently distinct rheumatic disease with a specific antibody to an extractable nuclear antigen (ENA). $A m \mathrm{~J} \mathrm{Med}$
1972; 52:148-59.

${ }^{21}$ Garvey JS, Cremer NE, Sussdorf DH. Methods in Immunology. Reading: Benjamin WA Inc, 1977: 175-8.

22 Olsson T, Henriksson A, Link H, Kristensson K. IgM and IgG responses during chronic relapsing allergic encephalomyelitis (r-EAE). J Neuroimmunol 1984; 6: 265-81.

${ }^{23}$ Norton WT, Poduslo SE. Myelination in rat brainchanges in myelin composition during brain maturation. J Neurochem 1973;21:759-73.

${ }^{24}$ Kadlubowski M, Hughes RA, Greyson NA. Experimental allergic neuritis in Lewis rat. - Characterization of the activity of peripheral myelin and its major basic protein $\mathrm{P}_{2}$. Brain Res $1980 ; 184: 439-54$.

${ }^{25}$ Vandenbark AA, VanRompaey F, Heyligen H, Nijst D, Raus J. CSF autoantibodies defect brain antigens. Protides Biological Fluids. XXX colloquim 1982: 231-4.

${ }^{26}$ Levfert AK, Link H. IgG production within the central nervous system - a critical review of proposed formulae. Protides Biological Fluids. XXXII colloquium 1984;6: 27.

${ }^{27}$ Sindic CJM, Cambinso CL, Depré A, Laterre EC, Masson PL. The concentration of IgM in the cerebrospinal fluid of neurological patients. J Neurol Sci 1982; 55:339-50.

${ }^{28}$ Roström B. Specificity of antibodies in oligoclonal bands in patients with multiple sclerosis and cerebrovascular disease. Acta Neurol Scand Suppl 86 1981:63.

${ }^{29}$ Roström B, Link H, Laurenzi MA, Kam-Hansen S, Norrby E, Wahren B. Viral antibody activity of oligoclonal and polyclonal immunoglobulins synthesized within the central nervous system in multiple sclerosis. Ann Neurol 1981;9:569-74.

30 Salmi A, Reunanen M, Ilonen J, Panelius M. Intrathecal antibody synthesis to virus antigens in multiple sclerosis. Clin Exp Immunol 1983;52:241-9. 